\title{
Effect of replacing surface with underground rubbish containers on urban House Sparrows Passer domesticus
}

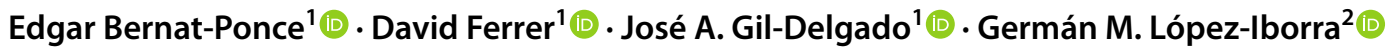

Accepted: 14 June 2021 / Published online: 28 June 2021

(c) The Author(s) 2021

\begin{abstract}
Urbanisation processes are increasing worldwide at surprising rates affecting wildlife in many ways: changing habitat structure, reducing resources, and modifying the distribution, composition and abundance of local biota. In different countries, urban waste collection techniques are evolving and surface rubbish containers (neighbourhood receptacles for temporarily storing anthropogenic household waste located above-ground on the streets) are being replaced with underground ones (metal boxes with steel chutes that fed into large underground containers) to improve sanitation measures, to avoid bad smells and waste scattering by animals. We aimed to detect if House Sparrows were more abundant close to surface rubbish containers than close to the underground ones. We recorded an abundance index of House Sparrows during two visits in winter 2018-2019 to point counts located in groups of both container types (80 and 85 groups of underground and surface containers, respectively) in eight towns of Eastern Spain. We modelled the abundance index according to rubbish container type, and 14 other environmental variables at four scales: container, nearest buildings, near urban features, and general locality features using GLMMs. House Sparrows were more abundant close to surface than to underground rubbish containers, which may be linked with higher food debris availability. The presence of other urban features (bar terraces, private gardens, mature trees) interacting with the rubbish containers also influenced the abundance of House Sparrows. The replacement of above-ground rubbish containers with underground ones may deprive House Sparrows resources, which could lead to the decline of this species, especially in urban areas with little green cover.
\end{abstract}

Keywords Anthropogenic food $\cdot$ Decline $\cdot$ Socio-economic level $\cdot$ Urban ecology $\cdot$ Urbanisation

\section{Introduction}

Urbanisation is increasing all over the world at surprisingly quick rates (Murgui and Hedblom 2017; United Nations 2018). This process affects wildlife in many ways, for

Edgar Bernat-Ponce

edgar.bernat@uv.es

David Ferrer

davidff16@gmail.com

José A. Gil-Delgado

gild@uv.es

Germán M. López-Iborra

german.lopez@uv.es

1 Cavanilles Institute of Biodiversity and Evolutionary Biology (Terrestrial Vertebrates Ecology/Department of Microbiology and Ecology), University of Valencia, Valencia, Spain

2 Departamento de Ecología/IMEM Ramon Margalef, Universidad de Alicante, Alicante, Spain example, modifying habitat structure which renders some landscapes unsuitable for several species (Bernat-Ponce et al. 2020; Isaksson 2018; Murgui and Hedblom 2017; Verbeeck et al. 2011). These modified environments pose a new challenge for urban avifauna through exposure to novel stressors, such as pollutants, noise, new predators, exotic competitors or processed food (Bernat-Ponce et al. 2018; Francis and Barber 2013; Herrera-Dueñas et al. 2017; Murgui and Hedblom 2017; Schroeder et al. 2012). This significant landscape transformation usually modifies local biota by bringing about changes in its distribution, composition, abundance and structure, or even leads some species to extinction (McKinney 2002; Shochat et al. 2010).

Despite the negative effects of urbanisation on individuals, populations and communities, some species manage to take advantage of several features they find in towns and cities. One of the main attractors for this group of animals to urban areas is constant human-induced food resources (Chace and Walsh 2006), provided intentionally by people such as feeders, or indirectly by rubbish containers or 
dumpsters (Bernat-Ponce et al. 2018; Reynolds et al. 2017; Tortosa et al. 2006). Thus, urban areas buffer seasonality effects concerning food availability (Murgui and Hedblom 2017).

The House Sparrow (Passer domesticus), native to most of Europe, Mediterranean basin and large parts of Asia (Anderson 2006), is a synanthropic species that over the last 50 years has sharply declined in many urban areas (Shaw et al. 2008; Summers-Smith 2003). However, the main cause of the species urban decline remains unclear (Anderson 2006; Summers-Smith 2005). A consensus is starting to emerge that considers the increase in human socio-economic status and urban renewal as key factors for the species' urban decline in Europe. First, changes in urban habitats and loss of green urban areas may negatively impact upon natural food availability, such as seeds and invertebrates (Bernat-Ponce et al. 2020; Pauleit et al. 2005; Vincent 2005). Second, these habitat changes have indirect effects on House Sparrows, such as a rising predation risk by Sparrowhawks (Accipiter nisus) and domestic cats (Felis catus) due to reduced shelter from predators (Bell et al. 2010; Shaw et al. 2008; Thomas et al. 2012). Finally, as House Sparrows are cavity nesters, nest site availability can diminish due to: changes in design, new materials in modern buildings and the refurbishment of older ones, especially in high income areas which decreases the number of crevices (Moudrá et al. 2018; Shaw et al. 2008). In addition, the competition for nest-sites between House Sparrows and larger invasive species could harm their populations (Charter et al. 2016).

House Sparrows have been human-commensals for more than 10,000 years (Sætre et al. 2012) and this worldwide success has been directly linked with their adaptation to feed on agricultural crops, poultry feed, and human subsidies (Anderson 2006; Bernis 1989; Whelan et al. 2015), and the use of human structures for nesting (Anderson 2006; Moudrá et al. 2018). The link of the House Sparrow with waste food is still important in modern urbanised areas. A previous study conducted in Spain showed that neighbourhood surface rubbish containers (large receptacles, dumpsters or skips, usually of 1000-3500 L of capacity for temporarily storing anthropogenic household waste located aboveground on the streets; see González-Torre et al. 2003 and Pires et al. 2019) were positively related to House Sparrow abundance, especially in winter (Bernat-Ponce et al. 2018). Food debris is usually found around surface rubbish containers as they are sometimes overfilled, and rubbish bags are deposited outside or sometimes they fall from the containers. Furthermore, surface rubbish containers are accessible to urban animals, such as cats, who break open bags and make the contents available to House Sparrows. In Lvov (Ukraine), a drastic reduction in the number of open surface rubbish containers in the city centre was followed by a rapid decline of House Sparrow populations (Bokotey and Gorban
2005). During the coldest season, natural trophic resources in urban landscapes are scarce and surface rubbish containers reliably provide anthropic high-calorific scraps, such as biscuits or snacks, around them (Bernat-Ponce et al. 2018; Bokotey and Gorban 2005; Herrera-Dueñas et al. 2015).

The effect of rubbish containers on House sparrow abundance is not independent of the influence of other urban landscape characteristics. For example, urban outdoor restaurants can attract House Sparrows to their surroundings as they are a reliable supply of food debris (Haemig et al. 2015). Wooded streets, private gardens and parks may provide shelter and food, especially by native plants (BernatPonce et al. 2018; Chamberlain et al. 2007; Murgui 2007, 2009). The height of the buildings and socio-economic level of the neighbourhood influence House Sparrow abundance (Bernat-Ponce et al. 2018; Shaw et al. 2008). Therefore, it is necessary to take into account the possible effect of urban features at several scales on House Sparrow abundance around rubbish containers.

Recently, neighbourhood underground rubbish containers system (large underground containers where rubbish enters through surface metal boxes with stainless steel chutes on the pavements; see "stand alone underground containers" in ISWA 2013) has spread in towns replacing neighbourhood surface rubbish containers. Even though underground systems are costly and technically more complex than surface containers they are installed to prevent bad odours, increase the cleanliness of urban areas, reduce the presence of mice, rats, cats, and invertebrate animals, save space, and avoid the negative visual effect of traditional neighbourhood aboveground rubbish containers (ISWA 2013; Nilsson 2011). For underground rubbish containers, rubbish bags disappear underground, and thus become inaccessible to House Sparrows. Several European urban areas in different countries, such as the United Kingdom, the Netherlands or Spain, among others (Eroski Consumer 2008; Interesting Engineering 2017; The Hague 2017), have replaced neighbourhood above-ground rubbish containers with underground rubbish containers in the last two decades (ISWA 2013; Nilsson 2011), especially in the centres of towns with higher socioeconomic levels (García-Hernández et al. 2017; INTHERWASTE 2019). However, this underground system is quickly spreading to other areas of the towns (ISWA 2013).

In the present study, we aimed to explore if sparrows were more abundant around above-ground rubbish containers than around underground rubbish containers, as well as the potential effects of other urban features surrounding the containers that could affect their use. We hypothesise that the replacement of neighbourhood above-ground rubbish containers with underground ones would have negative effects on House Sparrow populations. If this happens, the change in type of rubbish containers would be an additional mechanism contributing to the negative relation between House 
sparrow abundance and socioeconomic status proposed by Shaw et al. (2008).

\section{Methods}

\section{Study area and bird census}

The study was carried out in the Valencian Community (east Spain) (Fig. 1). This region presents a high availability of towns distributed along an altitudinal gradient where there has been a replacement of some neighbourhood aboveground rubbish containers by underground containers. We selected five coastal and three inland towns of several sizes (Table 1). They are representative localities in the study area, where $12 \%$ of towns are medium-sized $(15,000-60,000$ inhabitants) and $86 \%$ are small towns $(<15,000$ inhabitants $)$ (Table 1).

Both neighbourhood rubbish containers types, aboveground and underground (Fig. 2), are usually arranged in groups of several of the same type. The geographical location of rubbish container groups in each urban area was obtained from technical report maps owned by the Town Councils of the studied localities. We randomly selected a representative variable number of groups of underground rubbish containers at the eight localities, according to town size and containers availability $(\mathrm{n}=80$ in all; Table 1$)$. When two underground groups of containers fell within a $75 \mathrm{~m}$ radius, only one was selected for the study to avoid double counting. A similar number of surface rubbish containers per locality was also randomly selected $(n=85$ in all; Table 1) by following the same protocol to avoid double counting. Some groups of underground rubbish containers had an additional surface organic rubbish container, in which case this particular group of underground rubbish containers was discarded. Number of organic rubbish containers in each group was counted. At each selected group of containers we conducted $5 \mathrm{~min} 25 \mathrm{~m}$ fixed-radius point counts, centred at the rubbish container, and counted every House Sparrow seen and heard (Gibbons and Gregory 2006). Counting was done in December 2018, January 2019 and February 2019 (winter of 2018-2019) given the special relevance of human-related sources of food in winter (Bernat-Ponce et al. 2018; Bokotey and Gorban 2005). Each group of rubbish containers was sampled twice on two different days separated by a minimum of two-three weeks (First visit $=$ early winter; Second visit $=$ late winter). Counts were not done on windy and/or rainy days. Daily sampling sessions lasted approximately two hours, and started $15 \mathrm{~min}$ after the official sunrise time when this species is most active (Anderson 2006). On average, a sampling session comprised 14-18 point counts depending on the distance between consecutive sampling points.

For each group of containers we obtained 15 habitat variables potentially important for influencing House Sparrow presence and abundance (Table 2), including some of those proposed by Bernat-Ponce et al. (2018). These variables were classified into four sets that referred to urban landscape
Fig. 1 Map showing the eight selected urban areas to study the rubbish containers in east Spain: 1) Alcoy; 2) Onil; 3) Castalla;

4) Denia; 5) Jávea; 6) Alboraya;

7) Burjasot; 8) Vinaroz

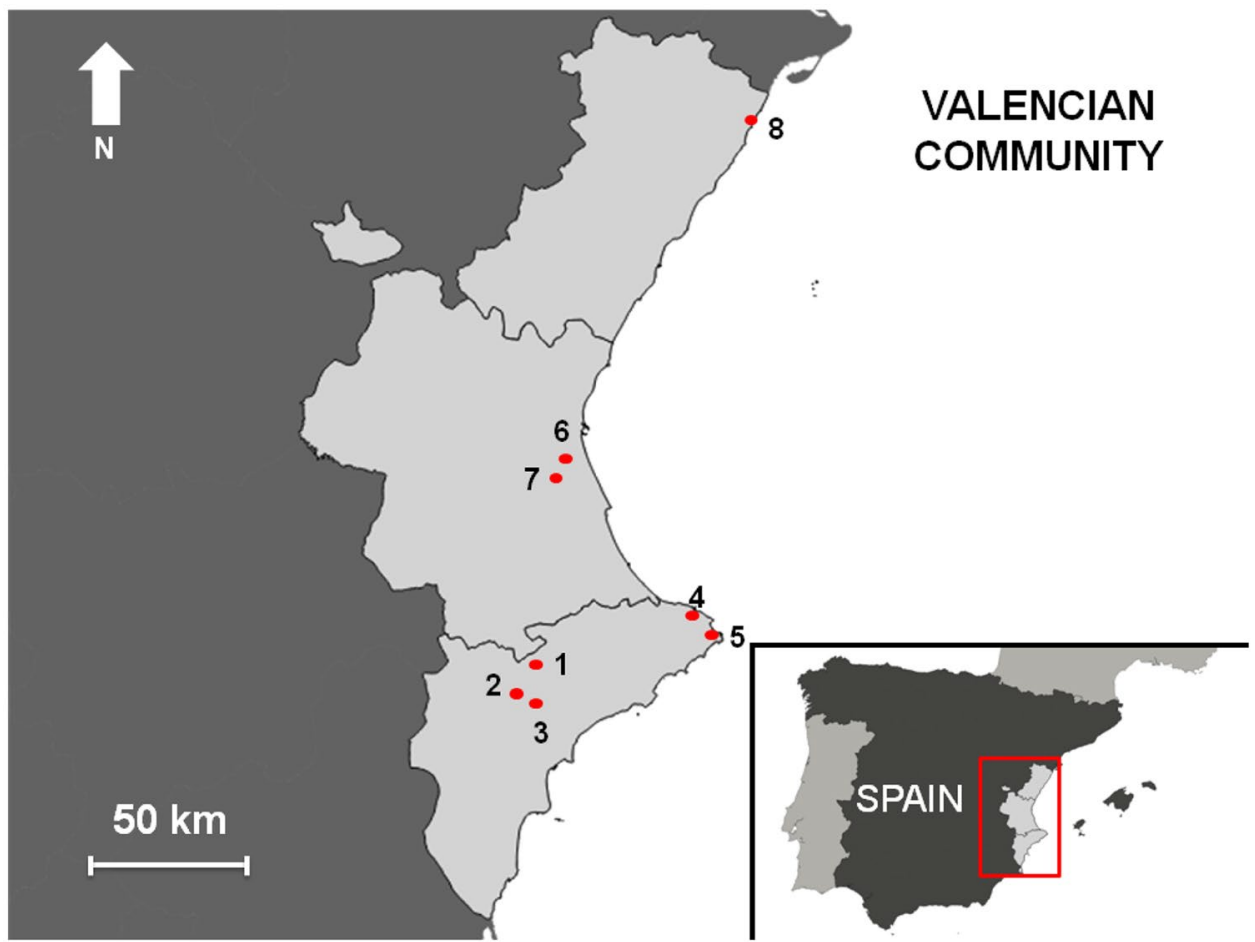


Table 1 Geographical, demographic, urban and climatic characteristics of the selected urban areas and information about the groups of rubbish containers studied in them. The number of studied groups of rubbish containers of each type is shown to the left of the slash; the available number is shown to the right of the slash. The number of total containers of each locality is shown in parentheses (when the numbers of groups is not reported, it is shown with -). Source: the authors with data from AVAMET (2019), Instituto Nacional de Estadística (2019), SIGPAC (2019) and technical reports from the localities

\begin{tabular}{|c|c|c|c|c|c|c|c|c|c|c|}
\hline \multirow[t]{2}{*}{ Locality } & \multirow[t]{2}{*}{ Coordinates } & \multirow{2}{*}{$\begin{array}{l}\text { Number of } \\
\text { inhabitants } \\
(2018)\end{array}$} & \multirow[t]{2}{*}{ Urban area (ha) } & \multicolumn{3}{|c|}{ Temperature ${ }^{\circ} \mathrm{C}(2018)$} & \multirow{2}{*}{$\begin{array}{l}\text { Rainfall } \\
\text { mm } \\
(2018)\end{array}$} & \multirow{2}{*}{$\begin{array}{l}\text { Altitude } \\
\text { (m.a.s.l.) }\end{array}$} & \multirow{2}{*}{$\begin{array}{l}\text { Underground } \\
\text { groups }\end{array}$} & \multirow{2}{*}{$\begin{array}{l}\text { Surface } \\
\text { groups }\end{array}$} \\
\hline & & & & Max. & Mean & Min. & & & & \\
\hline Alboraya & $\begin{array}{l}39^{\circ} 30^{\prime} 04^{\prime \prime} \mathrm{N} \\
0^{\circ} 20^{\prime} 58^{\prime \prime} \mathrm{W}\end{array}$ & 24,222 & 67.02 & 35.8 & 18.3 & 3.2 & 642.6 & 5 & $8 / 14(28)$ & $8 /-(212)$ \\
\hline Alcoy & $\begin{array}{l}38^{\circ} 41^{\prime} 54^{\prime \prime} \mathrm{N} \\
0^{\circ} 28^{\prime} 25^{\prime \prime} \mathrm{W}\end{array}$ & 58,977 & 349.03 & 40.4 & 16.1 & -4.4 & 439.2 & 562 & $8 / 12(25)$ & 10/141(294) \\
\hline Burjasot & $\begin{array}{l}39^{\circ} 30^{\prime} 33^{\prime \prime} \mathrm{N} \\
0^{\circ} 24^{\prime} 39^{\prime \prime} \mathrm{W}\end{array}$ & 37,584 & 194.74 & $38.5^{\mathrm{a}}$ & $17.6^{\mathrm{a}}$ & 2.8 & $658.6^{\mathrm{a}}$ & 59 & $14 /-(50)$ & $14 /-(242)$ \\
\hline Castalla & $\begin{array}{l}38^{\circ} 35^{\prime} 48^{\prime \prime} \mathrm{N} \\
0^{\circ} 40^{\prime} 15^{\prime \prime} \mathrm{W}\end{array}$ & 9880 & 85.74 & - & - & -1.7 & 418.8 & 675 & $6 / 52(52)$ & $6 / 27(27)$ \\
\hline Denia & $\begin{array}{l}38^{\circ} 50^{\prime} 25^{\prime \prime} \mathrm{N} \\
0^{\circ} 06^{\prime} 31^{\prime \prime} \mathrm{E}\end{array}$ & 41,733 & 99.80 & 37.8 & 19.5 & 5.3 & 625.8 & 12 & $17 / 60(112)$ & $17 / 65(520)$ \\
\hline Jávea & $\begin{array}{l}38^{\circ} 47^{\prime} 21^{\prime \prime} \mathrm{N} \\
0^{\circ} 09^{\prime} 47^{\prime \prime} \mathrm{E}\end{array}$ & 27,224 & 171.1 & 36.9 & 19.1 & 4.4 & 675.6 & 12 & $13 /-(30)$ & $16 /-(325)$ \\
\hline Onil & $\begin{array}{l}38^{\circ} 37^{\prime} 46^{\prime \prime} \mathrm{N} \\
0^{\circ} 40^{\prime} 26^{\prime \prime} \mathrm{W}\end{array}$ & 7475 & 77.76 & 34.8 & 14.5 & -4.2 & 360.6 & 715 & 4/ 5 (11) & 4/- (98) \\
\hline Vinaroz & $\begin{array}{l}40^{\circ} 28^{\prime} 00^{\prime \prime} \mathrm{N} \\
0^{\circ} 28^{\prime} 00^{\prime \prime} \mathrm{E}\end{array}$ & 28,438 & 97.50 & 35.1 & 18.2 & 1.6 & 785.9 & 7 & $10 / 12(25)$ & $10 /-(260)$ \\
\hline
\end{tabular}

${ }^{\text {a }}$ Corresponds to the adjacent town (Moncada) due to the incomplete series in Burjasot

characteristics on different scales. The first set of variables defined the features of the rubbish containers: type of container (surface or underground) and number of containers intended to receive rubbish containing organic matter. The second set of variables described the features of the closest buildings at the sampling point: mean number of floors of the eight nearest buildings; the socio-economic level of the area where rubbish containers are located, classified into

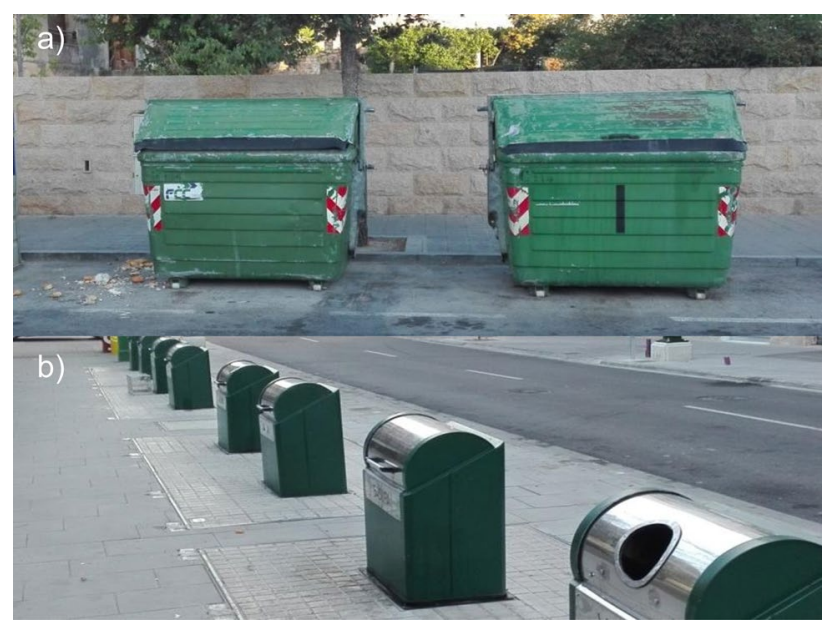

Fig. 2 Types of rubbish containers in this study. a) Neighbourhood surface rubbish containers. b) Neighbourhood underground rubbish containers deprived area, average area, and well-off/high income area (Bernat-Ponce et al. 2018; Shaw et al. 2008). The third set described the urban features in the sampling point and its adjacent habitat (50 $\mathrm{m}$ radius): presence/absence of private gardens; presence/absence of bar terraces; presence/ absence of schools; presence/absence of parks; presence/ absence of mature trees on streets; if the sampling point was in the centre of the urban area (defined as the oldest sector of the urban area, where commercial and business activities tend to concentrate) or not. We used a $50 \mathrm{~m}$ radius because this represents the average home range of urban House Sparrows (0.86 ha; Vangestel et al. 2010). The last set included variables associated with the locality's general features (town/city scale): geographical location (coastal or inland); socio-economic level of the sampled locality defined by the average budget per inhabitant (ARGOS 2019); number of inhabitants (Instituto Nacional de Estadística 2019); ratio of surface rubbish containers per inhabitant in the locality; ratio of underground rubbish containers per inhabitant in the locality.

\section{Statistical analysis}

Statistical analyses were carried out in RStudio 3.6.1. We used Generalized Linear Mixed Models (GLMMs) to identify the variables in each of the four aforementioned sets that were related most to the House Sparrow number counted at each point (dependent variable). The $\mathrm{R}$ 
Table 2 Environmental variables tested for their effect on House Sparrow abundance around groups of rubbish containers in urban areas of east Spain in winter

\begin{tabular}{|c|c|c|c|c|c|}
\hline Set and sampling scale & Variable & Abbreviation & Type & Sampled/Obtained & Description \\
\hline \multicolumn{6}{|l|}{ 1. Container features } \\
\hline \multirow[t]{2}{*}{ (sampling point) } & Rubbish container & CONT & Categorical & In situ & Underground /Surface \\
\hline & Number of containers & NCONT & Numerical & In situ & $\begin{array}{l}\text { Number of containers at the } \\
\text { group }\end{array}$ \\
\hline \multicolumn{6}{|l|}{ 2. Building features } \\
\hline \multirow[t]{2}{*}{ (sampling point) } & Mean building height & BUILD & Numerical & In situ & $\begin{array}{l}\text { Mean number of floors (eight } \\
\text { nearest buildings) }\end{array}$ \\
\hline & Socio-economic level point & SOCLEVP & Categorical & In situ & Deprived/Average/Well-off \\
\hline \multicolumn{6}{|l|}{ 3. Urban features } \\
\hline \multirow[t]{6}{*}{ (50 $\mathrm{m}$ radius) } & Private garden & PG & Categorical & SIGPAC (2019) & Absence/Presence \\
\hline & Terrace & TERR & Categorical & SIGPAC (2019) & Absence/Presence \\
\hline & School & $\mathrm{SCH}$ & Categorical & SIGPAC (2019) & Absence/Presence \\
\hline & Park & PARK & Categorical & SIGPAC (2019) & Absence/Presence \\
\hline & Tree & TREE & Categorical & In situ & Absence/Presence \\
\hline & Centre & CENT & Categorical & SIGPAC (2019) & $\mathrm{No} / \mathrm{Yes}$ \\
\hline \multicolumn{6}{|l|}{ 4. Locality features } \\
\hline \multirow[t]{5}{*}{ (Town scale) } & Altitude & ALT & Categorical & & Coastal/Inland \\
\hline & No. inhabitants & INHAB & Numerical (scaled) & $\operatorname{INE}^{\mathrm{a}}(2019)$ & \\
\hline & Socio-economic level locality & SOCLEVL & Numerical (scaled) & ARGOS (2019) & Average budget per inhabitant \\
\hline & $\begin{array}{l}\text { Ratio of underground contain- } \\
\text { ers }\end{array}$ & RATUND & Numerical (scaled) & SIGPAC (2019) & $\begin{array}{l}\text { Number of underground } \\
\text { containers/inhabitant }\end{array}$ \\
\hline & Ratio of surface containers & RATSURF & Numerical (scaled) & SIGPAC (2019) & $\begin{array}{l}\text { Number of surface containers } \\
\text { inhabitant }\end{array}$ \\
\hline
\end{tabular}

${ }^{a}$ Instituto Nacional de Estadística 2019

package "glmmTMB" (Brooks et al. 2017) was used to fit the GLMMs. The container group identity code was included as a random factor because repeated measures were done at each group of containers (O'Hara 2009). The environmental variables were treated as fixed effects. Number of inhabitants, socio-economic level of the locality and both the ratios of underground/surface rubbish containers per inhabitant in the locality that formed part of the locality's features group were scaled (centred and divided by standard deviations) using the "scale" function in R. Moreover, in the models we included three variables as fixed effects to consider the space or time effect. The spatial autocorrelation effect was controlled by including a spatial term (SPAT) with the coordinates of the form ' $x+y+x^{2}+x y+y^{2}+x^{3}+x^{2} y+x y^{2}+y^{3}$ in all analyses (Legendre and Legendre 1998; López-Pomares et al. 2015). The name of the locality (LOC) was included to control for the locality effect on each group, except for the group describing the locality's general features. The visit (VISIT, first or second) was also included to take temporal variability into account and to check if there were any differences between them (early winter/late winter).

To avoid including a high number of variables and interactions in the analyses the following statistical proceeding was followed for each set of variables. First of all, we fitted a complete GLMM with all the environmental variables in the set, the spatial-time variables and only the interactions that we considered to be biologically meaningful. We started fitting the complete model with Poisson distribution. We tested this model for overdispersion with the "check_overdispersion" function of the "performance" package (Lüdecke et al. 2019). We also fitted two variants of the same model using Negative Binomial distribution type 1 (family nbinom1) and type 2 (family nbinom 2 ) (Blasco-Moreno et al. 2019). Then we selected the model variant with the family that yielded the lowest SecondOrder Akaike Information Criterion (AICc) calculated with the appropriate function of the "MuMIn" package (Barton 2019).

The multicollinearity of the variables included in each model was checked with the "check_collinearity" function of the "performance" package (Lüdecke et al. 2019). The significance of the fixed effects was tested by the "Anova" function of the "car" package (Fox and Weisberg 2019). We considered multicollinearity to be high when VIF was $>5$ (Zuur et al. 2010). In these cases we first attempted to reduce multicollinearity by deleting the interaction between variables with VIF $>5$. If several interactions presented similar high VIF values, 
that with the lowest significance in GLMMs was eliminated. When no multicollinear interactions remained, the same procedure was repeated for the multicollinear main effects. Then the GLMMs in each group of variables were simplified by deleting the least significant interactions in turn and by checking if this deletion was linked to a reduction in the AICc. If this proceeding did not reduce the AICc, the least significant main effect was deleted instead, provided it was not included in the remaining interactions, and AICc reduction was checked. The final model was that with the lowest possible AICc after deleting the non-significant variables/ interactions.

The variables included in the final model and the equally plausible models $(\Delta \mathrm{AICc}<2)$ of each set were selected for checking in a final combined analysis with the variables selected from all the four sets, along with their biologically interesting interactions and the spatial-time variables (SPAT, LOC, VISIT). This combined GLMM was simplified by following the aforementioned proceeding to obtain a final set of equally plausible models $(\Delta$ AICc $<2)$. Given the large number of variables in the combined analysis, the process of eliminating multicollinear terms was done in two steps to avoid convergence problems in the models. First of all, the variables selected from the first three sets were checked together to eliminate multicollinear terms. Then the remaining terms were joined to the selected variables of the fourth set (locality features) to detect and eliminate additional collinear terms. For the best models, we calculated the conditional intraclass correlation (cICC) to estimate the proportion of variance in abundance that was accounted for by the random effect using the "icc" function of the package "sjstats" (Lüdecke 2019) and the conditional $\mathrm{R}^{2}$ to obtain the variance explained by the entire model, including both fixed and random effects with the "r.squaredGLMM" function of the "MuMIn" package (Bartoń 2019).

Comparison of the socioeconomic level and building and urban features around groups of containers located in the centre or the outskirts of urban areas can be found in Appendix A (Online Resource). We tested if these variables differed between urban sectors (centre or outskirts) and container type (underground or surface) using loglinear models for categorical variables (SOCLEVP, PG, TERR, SCHO, PARK, TREE) and ANOVA test for the continuous variable (height of buildings, BUILD). These analyses were carried out with the "lm" and "aov" functions from the "stats" package (R Core Team 2020), and the "anova" function from the "car" package (Fox and Weisberg 2019). Mean number of containers per group were compared between container types using the function "wilcox.test" of the package "stats" (R Core Team 2020).

\section{Results}

Mean number of containers in underground groups of rubbish containers was significantly higher than in surface groups (Underground: $1.93 \pm 0.07 \mathrm{SE}$; Surface: $1.59 \pm 0.09$ $\mathrm{SE}$; Wilcoxon $\mathrm{W}=2290.5 ; \mathrm{p}<0.001)$. House sparrows were frequently found around rubbish containers as they were detected in $90-97 \%$ of surface containers and $65-81 \%$ of underground containers. Even though no overdispersion was detected in the Poisson family models, GLMMs were fitted using Negative Binomial distribution type 1 (nbinom1 family) because they had lower AICc values (Appendix B-Online Resource). The simplification process of GLMMs for each set of variables and the combined model are found in Appendix C (Online Resource). The final model for the variables related to container features included the container type, spatial term and visit, which were all significant. The final model for the building feature variables included the mean number of floors, the visit and the spatial term, all significant. The variables associated with urban features included in the final model were: private gardens; mature trees; bar terraces; location of the point count in the centre; the centre-visit interaction; the visit and the spatial term. In the group of variables related to locality features, the following variables were selected: socio-economic level; ratio of surface containers per inhabitant and its interaction with visit; altitude and its interaction with visit; the spatial term and visit.

The combined GLMMs showed that three final models were equally plausible $(\Delta \mathrm{AICc}<2)($ Table 3$)$. The model with the lowest AICc (Model 1; AICc $=1750.6$ ) was built with the variables container type (CONT), private garden (PG), mature trees (TREE), bar terraces (TERR), centre (CENT), spatial term (SPAT) and visit (VIS); with four interactions: centre (CENT) with visit (VIS); container type (CONT) with private garden (PG); centre (CENT) with container type (CONT); mature trees (TREE) with centre (CENT). Model coefficients were all significant $(p<0.05)$, except for the variable TREE $(p=0.06)$, the variable CENT $(p=0.168)$ and the interaction CENT with CONT $(p=0.104)$ (Table 3$)$. There were two other equally plausible models. The first was like Model 1 but without the CENT with CONT interaction (Model 2; AICc $=1751.0$ ); the second resulted from adding the variable BUILD to Model 1 (Model 3; AICc $=1751.9)$ (Table 3).

All the final models showed that the rubbish container type is related to the abundance of the House Sparrows around them. This species was more abundant in those areas with surface rubbish containers than in the areas where rubbish containers were located underground. Presence of bar terraces was also related to the abundance of House Sparrows, regardless of the container type in their 
Table 3 Best final combined GLMM models (nbinom1 family) built with the variables selected from the four sets. Models are ordered by AICc value (Second-order Akaike Information Criterion). cICC: conditional intraclass correlation coefficient. $\mathrm{R}^{2}$ interpreted as a $\%$ of variance explained by the entire model, including both fixed and random effects. Significant $\mathrm{p}$ values are marked with $(*)=\mathrm{p}<0.05$; $(* *)=\mathrm{p}<0.01 ;(* * *)=\mathrm{p}<0.001$, and marginally significant $\mathrm{p}$ values with ()$=p<0.1$. Brackets identify the level of the factor at which the model coefficients were calculated

\begin{tabular}{|c|c|c|c|c|c|c|}
\hline Model & $\mathrm{AICc}$ & $\mathrm{R}^{2}$ & Set & Variables & Estimate & $p$ \\
\hline \multirow[t]{15}{*}{1} & 1750.6 & 91.0 & & Intercept & 0.834 & \\
\hline & & & & Fixed & & \\
\hline & & & 1 & CONT & -0.725 (UNDERGROUND) & $<0.001 * * *$ \\
\hline & & & 3 & CENT & $-0.385(\mathrm{YES})$ & 0.168 \\
\hline & & & & PG & 0.106 (PRESENCE) & $0.002 * *$ \\
\hline & & & & TERR & 0.238 (PRESENCE) & $0.017 *$ \\
\hline & & & & TREE & -0.288 (PRESENCE) & $0.060^{\circ}$ \\
\hline & & & Control & SPAT & 0.182 & $<0.001 * * *$ \\
\hline & & & & VIS & 0.050 (SECOND) & $0.042 *$ \\
\hline & & & Interactions & $\mathrm{CENT}^{*} \mathrm{CONT}$ & -0.332 (CENT YES * CONT UNDERGROUND) & 0.104 \\
\hline & & & & CENT*VIS & $0.282(\mathrm{CENT}$ YES * SECOND) & $0.030^{*}$ \\
\hline & & & & $\mathrm{PG} * \mathrm{CONT}$ & 0.451 (PG PRESENCE * CONT UNDERGROUND) & $0.015^{*}$ \\
\hline & & & & TREE*CENT & 0.442 (TREE PRESENCE * CENT YES) & $0.030^{*}$ \\
\hline & & & & Random & & \\
\hline & & & & CONT-ID & Variance (0.148) cICC (0.182) & \\
\hline \multirow[t]{14}{*}{2} & 1751.0 & 90.9 & & Intercept & 0.874 & \\
\hline & & & & Fixed & & \\
\hline & & & 1 & CONT & -0.823 (UNDERGROUND) & $<0.001 * * *$ \\
\hline & & & 3 & CENT & $-0.522(\mathrm{YES})$ & 0.165 \\
\hline & & & & PG & 0.071 (PRESENCE) & $0.005 * *$ \\
\hline & & & & TERR & 0.260 (PRESENCE) & $0.009^{*}$ \\
\hline & & & & TREE & -0.279 (PRESENCE) & 0.062 \\
\hline & & & Control & SPAT & 0.181 & $<0.001 * * *$ \\
\hline & & & & VIS & $0.050(\mathrm{SECOND})$ & $0.044^{*}$ \\
\hline & & & Interactions & CENT*SUR & 0.278 (CENT YES * SECOND) & $0.033^{*}$ \\
\hline & & & & $\mathrm{PG} * \mathrm{CONT}$ & 0.483 (PG PRESENCE * CONT UNDERGROUND) & $0.010 * *$ \\
\hline & & & & TREE*CENT & 0.399 (TREE PRESENCE * CENT YES) & $0.050^{*}$ \\
\hline & & & & Random & & \\
\hline & & & & CONT-ID & Variance $(0.154)$ cICC $(0.191)$ & \\
\hline \multirow[t]{16}{*}{3} & 1751.9 & 91.0 & & Intercept & 0.978 & \\
\hline & & & & Fixed & & \\
\hline & & & 1 & CONT & -0.702 (UNDERGROUND) & $<0.001 * * *$ \\
\hline & & & 2 & BUILD & -0.035 & 0.334 \\
\hline & & & 3 & CENT & $-0.420(\mathrm{YES})$ & 0.121 \\
\hline & & & & PG & 0.087 (PRESENCE) & $0.005^{* *}$ \\
\hline & & & & TERR & 0.242 (PRESENCE) & $0.015^{*}$ \\
\hline & & & & TREE & -0.282 (PRESENCE) & 0.073 \\
\hline & & & Control & SPAT & 0.181 & $<0.001 * * *$ \\
\hline & & & & VIS & 0.050 (SECOND) & $0.042 *$ \\
\hline & & & Interactions & $\mathrm{CENT}^{*} \mathrm{CONT}$ & -0.331(CENT YES * CONT UNDERGROUND) & 0.105 \\
\hline & & & & CENT*VIS & 0.282 (CENT YES * SECOND) & $0.030^{*}$ \\
\hline & & & & $\mathrm{PG} * \mathrm{CONT}$ & 0.444 (PG PRESENCE * CONT UNDERGROUND) & $0.017 *$ \\
\hline & & & & TREE*CENT & 0.457 (TREE PRESENCE * CENT YES) & $0.025^{*}$ \\
\hline & & & & Random & & \\
\hline & & & & CONT-ID & Variance $(0.146)$ cICC $(0.180)$ & \\
\hline
\end{tabular}


vicinity. On the contrary, presence of private gardens was positively related to House Sparrow abundance only around underground rubbish containers (Fig. 3a). These models also showed that mature trees on streets were negatively correlated to the abundance of the House Sparrows around containers. However, the interaction between the presence of mature trees and location at the centre of the urban area showed that the absence of trees contributed to lower House Sparrow numbers in outskirt areas while had not effect in the urban centre (Fig. 3b). Furthermore, spatial term and visit were significant. The significant interaction between visit and centre revealed that House Sparrow abundance index significantly increased during the second visit only around containers in central areas of towns (Fig. 3c). The cICC of the three final models ranged between 0.180 and 0.191 , thus around $20 \%$ of variance in the House Sparrow abundance index was due to the rubbish containers group's identity. The variance explained by the three models was similar and around $90 \%$.

\section{Discussion}

Our results showed that House Sparrows were less abundant around underground rubbish containers than around surface containers. However, the House Sparrow abundance around rubbish containers was also influenced by other urban habitat characteristics. On one hand, the presence of bar terraces around rubbish containers was in general associated with higher House Sparrow abundance while presence of private gardens was related to higher House Sparrow abundance only around underground containers. On the other hand
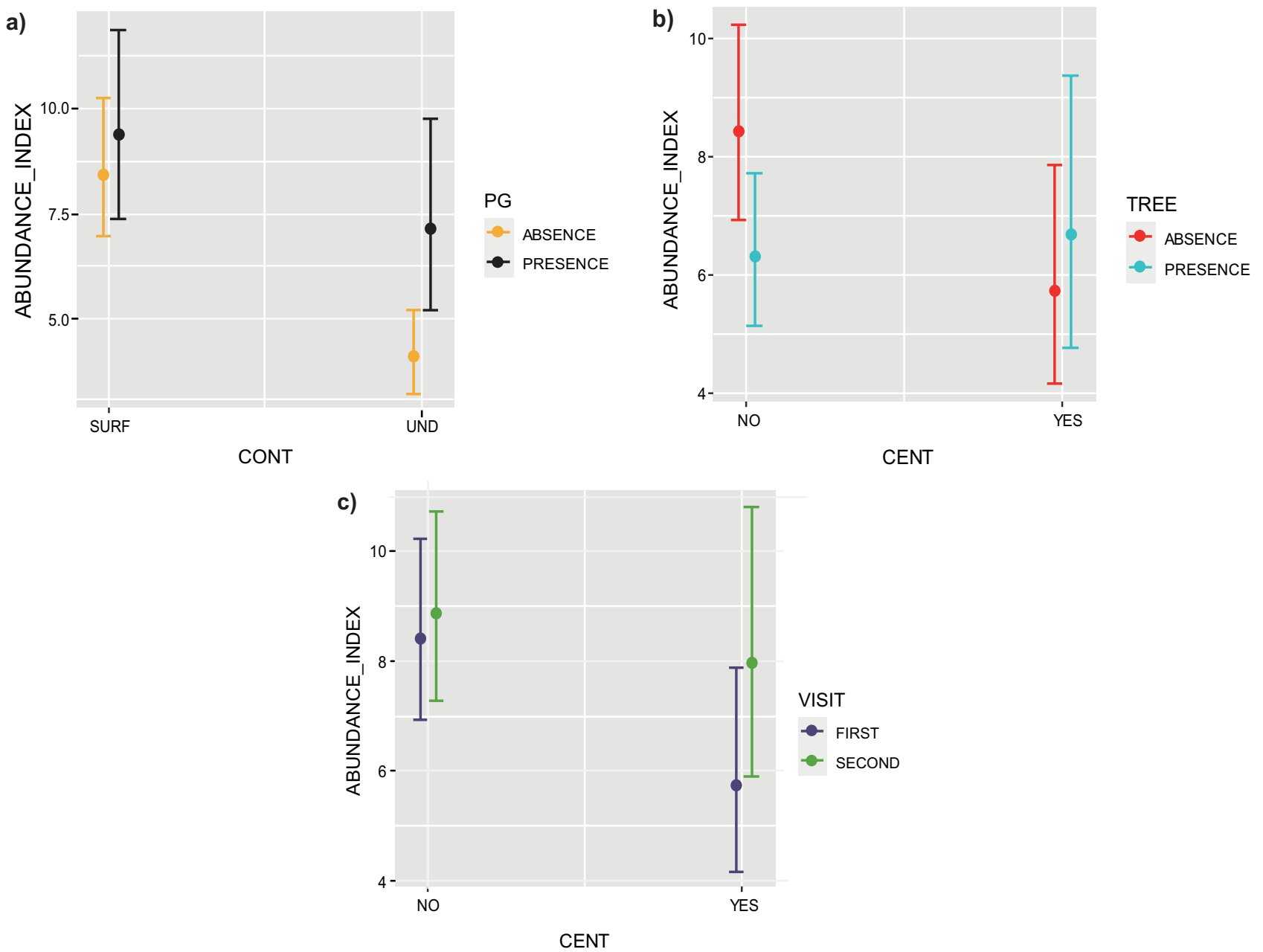

Fig. 3 Graphs of the significant interactions detected in GLMMs (Table 3). Predictions of the abundance indices of House Sparrows were calculated using Model 1. a) Interaction between rubbish container type and presence/absence of private gardens. b) Interaction between location at the centre of the urban area and presence of mature trees in streets. c) Interaction between location at the centre of the urban area and visit. CONT: Rubbish container; SURF: Surface rubbish containers; UND: underground rubbish containers; PG: Private gardens; CENT: Centre of urban area; TREE: Presence of mature trees 
presence of mature trees around containers located at outskirts was negatively related to House Sparrow abundance.

It is assumed that the main reason for House Sparrows association to rubbish containers is that birds easily find scraps of anthropogenic food, usually of high calorific value, in their surroundings and in fact sparrows are frequently seen pecking on the ground around these places (pers. obs.). This situation seems to be especially important in winter, when natural food in urban areas can be scarcer or harder to obtain as Bokotey and Gorban (2005), and Bernat-Ponce et al. (2018) found in Ukraine and Spain, respectively. A limitation of the present study is that we assumed that trophic resources were more abundant around surface than around underground containers but we did not actually quantify their abundance. The design and functioning of each container type are so distinct that we expected some difference in abundance of food scraps around them, and this should be an intended consequence of the design of underground containers. Therefore, it seems reasonable that the reduced abundance of House Sparrows recorded around underground rubbish containers reflects the increase in cleanliness associated to underground containers. Replacing surface rubbish containers by underground ones is a growing urban trend in European cities to improve sanitation measures (Eroski Consumer 2008; Interesting Engineering 2017; The Hague 2017). This trend could lead to a potential limitation of the number of sparrows that these areas can maintain. However, future studies should check the assumption of different abundance of food scraps around container types or other urban features as well as their temporal variation along the day, which could help to explain some of the patterns of urban habitats use by House Sparrows.

Bar terraces around rubbish containers were associated with higher House Sparrow abundance because they are an important supply of anthropogenic debris (Haemig et al. 2015). No matter what type of rubbish container group was studied, House Sparrows were always more abundant when bar terraces were present. However, this link between House Sparrows and bar terraces was not found in east Spain by Bernat-Ponce et al. (2018). This difference could be due to differences in the sampling design between the studies because sampling point counts of the present research were located, exclusively, in the vicinity of rubbish containers, while the other study considered the entire urban matrix. The presence of bar terraces and containers could have a synergic effect on House Sparrows' abundance, since both provide food resources in complementary times, and therefore the effect of bar terraces could be easier to detect in the proximity of rubbish containers. Bernat-Ponce et al. (2018) found that urban parks were positive for the abundance of House Sparrows while in the present study we did not find this effect around rubbish containers of any type. In the aforementioned study, most point counts in parks were located inside them and not on their surrounding streets, where rubbish containers were located. Parks might offer alternative abundant natural food resources that could reduce the link between House Sparrows and urban rubbish containers located on their edge, or even could reduce their detectability due to the presence of abundant vegetation. Conversely, private gardens had an effect only on sparrow abundance around underground containers, where they partially mitigate reduced House Sparrow abundance compared to surface containers. Thus the effect of private gardens seemed weaker than that of bar terraces. This is likely explained by the variability in the quality of these gardens as a habitat for sparrows. Even though some Spanish gardens could provide shelter and food from native vegetation, they are usually very small, mostly planted with exotic species that do not produce berries, and food provision for birds by owners (e.g. bird feeders) is not as frequent as in other European countries. Consequently, we may expect food availability in private gardens to be lower and more unpredictable than on bar terraces. However, Chamberlain et al. (2007), Murgui (2009), and Shaw et al. (2008) found that these gardens were a key factor for the House Sparrow abundance in urban environments of the UK and Spain. Therefore, it would appear that the importance of some urban landscape components for House Sparrows may differ between localities, depending on their specific characteristics, as Murgui (2009) suggested to explain the discrepancies among several studies.

Presence of trees in the vicinity of rubbish container groups studied in the centre of urban areas had no effect on the abundance of House Sparrows, but trees had a negative effect on sparrow abundance around containers located at outskirts. This was an unexpected result as we thought that trees could be used as a shelter and a food supply, and would always have a positive effect. Several explanations are possible for this effect of trees. As the presence of mature trees around rubbish containers was similar in the centre and outskirts (Appendix A-Online Resource) this result might be due to the different features of wooded areas. When present in outskirts, trees tend to be located on avenues which cover larger areas, where House Sparrows would be less linked with rubbish containers and would, therefore, group less around them than in the centre. In addition, House Sparrows also tend to be more abundant in outskirts (Fig. 3c this paper; Murgui 2009), thus when trees are absent, the House Sparrow grouping around rubbish containers would be more evident than in the town centre.

Visit had no effect on the House Sparrow abundance around the containers located in outskirts, while more birds were counted during the second visit (late winter) in the centre. Variation in the urban landscape between centre and outskirts could help to explain this interaction. Schools, bar terraces, and private gardens, which are associated with more abundance of food (Gaston et al. 2005; Haemig et al. 
2015; Spelt et al. 2021), tend to be more frequent in outskirts (see Appendix A, Online Resource) and therefore House Sparrows should concentrate more around rubbish containers in town centres during the harshest winter period than in outskirts. Finally, no variable related to the locality's general characteristics was selected in the final models. As we have seen, all the significant variables explaining the abundance of House Sparrows around rubbish containers were related to the presence of some particular urban features around them. This suggests that the pattern found herein was the same in all the studied towns and supports the view that the container type effect we detected in this work is likely generalizable to other cities in different geographical locations.

Evidence reveals that replacing surface rubbish containers with underground rubbish containers is associated with a reduction of House Sparrows abundance around them. As urban cleanliness is a social demand and is correlated with positive outcomes (high hygienic standards, avoiding odours, etc.) (ISWA 2013), we do not advocate removing underground containers and return to surface waste collecting systems. However, we believe that it is important to be aware that an increase in underground rubbish containers would add another negative impact on House Sparrows in modern cities and, thus, compensatory measures that increase food supply in other urban landscape component should be taken to mitigate its impact. First, design and management of green areas should promote weeds, bushes and native plants that harbour important food resources for House sparrows such as invertebrates and seeds (BernatPonce et al. 2018; Narango et al. 2018). The substitution of grass and soil with impervious substrates such as artificial grass and concrete has been shown to affect negatively to House sparrows (Bernat-Ponce et al. 2020; Verbeeck et al. 2011), likely due to the reduction of food resources and thus should be avoided. Second, it is important to promote new urban green areas that work as green stepstones, including parks and private gardens, especially in areas with underground rubbish containers (De Laet and Trappeniers 2019; Shaw et al. 2011). More research is urgently needed to precisely identify the short-, mid- and long-term effects of urban diet on urban wildlife and to boost alternative trophic resources through green urban planning.

Supplementary Information The online version contains supplementary material available at https://doi.org/10.1007/s11252-021-01138-y.

Acknowledgements We acknowledge Jenny De Laet for a preliminary check of this manuscript. We thank Susannah Lerman (Associate Editor) and an anonymous reviewer for critically reviewing and improving the manuscript. We thank Helen Warburton (Traducciones hya) and Ana I. Martínez for their English check and edition. We thank Ángel Gálvez for his help with figures.

Authors' contributions E.B-P. and J.A.G-D. conceived of the study idea. E.B-P., J.A.G-D. and G.M.L-I. designed the fieldwork. All authors collected field data. E.B-P., J.A.G-D. and G.M.L-I. contributed to the analysis of the results and to the writing of the manuscript. All authors read and approved the final manuscript.

Funding Open Access funding provided thanks to the CRUE-CSIC agreement with Springer Nature. This research was supported by a $\mathrm{PhD}$ grant of the Generalitat Valenciana and the European Social Fund (E.B-P., grant number ACIF/2018/015). Fieldwork was supported by a collaboration grant for research purposes of the Ministerio de Educación y Formación Profesional - Gobierno de España (D.F., BecaColaboración Curso 2018/2019 Código 998142). The open-access publication fees of this research were covered by the Universitat de València through the Transformative Agreement between Springer Nature and Crue \& CSIC.

Data availability Data available on request from the authors

Code availability Code ( $\mathrm{R}$ software) available on request from the authors

\section{Declarations}

Conflicts of interest/Competing interests The authors declare that they have no conflict of interest.

Open Access This article is licensed under a Creative Commons Attribution 4.0 International License, which permits use, sharing, adaptation, distribution and reproduction in any medium or format, as long as you give appropriate credit to the original author(s) and the source, provide a link to the Creative Commons licence, and indicate if changes were made. The images or other third party material in this article are included in the article's Creative Commons licence, unless indicated otherwise in a credit line to the material. If material is not included in the article's Creative Commons licence and your intended use is not permitted by statutory regulation or exceeds the permitted use, you will need to obtain permission directly from the copyright holder. To view a copy of this licence, visit http://creativecommons.org/licenses/by/4.0/.

\section{References}

Anderson TR (2006) Biology of the Ubiquitous House Sparrow: from genes to populations. Oxford University Press, Oxford

ARGOS (2019) Portal d'Informació ARGOS (ARGOS Information Portal). Generalitat Valenciana. http://www.argos.gva.es/ bdmun/pls/argos_mun/DMEDB_MUNLISTADO.dibujaPagina? aNComuId=17\&aVLetra=A\&aVLengua $=c$. Accessed 20 Dec 2019

AVAMET (2019) Meteoxarxa, Estadístiques. Associació Valenciana de Meteorologia 'Josep Peinado' (Meteoweb, Statistics. Valencian Association of Meteorology 'Josep Peinado'). https://www. avamet.org/. Accessed 14 Dec 2019

Bartoń K (2019) Package "MuMIn". https://cran.rproject.org/web/ packages/MuMIn/MuMIn.pdf. Accessed 14 Dec 2019

Bell CP, Baker SW, Parkes NG, de Brooke M, L, Chamberlain DE, (2010) The role of the Eurasian Sparrowhawk (Accipiter nisus) in the decline of the House Sparrow (Passer domesticus) in Britain. Auk 127:411-420. https://doi.org/10.1525/auk.2009. 09108

Bernat-Ponce E, Gil-Delgado JA, Guijarro D (2018) Factors affecting the abundance of House Sparrows Passer domesticus in urban areas of southeast of Spain. Bird Study 65:404-416. https://doi. org/10.1080/00063657.2018.1518403

Bernat-Ponce E, Gil-Delgado JA, López-Iborra GM (2020) Replacement of semi-natural cover with artificial substrates in urban parks 
causes a decline of house sparrows Passer domesticus in Mediterranean towns. Urban Ecosyst 23:471-481. https://doi.org/10.1007/ s11252-020-00940-4

Bernis F (1989) Los gorriones. Con especial referencia a su distribución y eto-ecología en las mesetas españolas (The Sparrows. With special reference to their distribution and eto-ecology in the Spanish plateaus). I.N.I.A., Ministerio de Agricultura, Pesca y Alimentación, Madrid

Blasco-Moreno A, Pérez-Casany M, Puig P, Morante M, Castells E (2019) What does a zero mean? Understanding false, random and structural zeros in ecology. Methods Ecol Evol 10:949-959. https://doi.org/10.1111/2041-210X.13185

Bokotey AA, Gorban IM (2005) Numbers, distribution and ecology of the House Sparrow in Lvov (Ukraine). Intern Stud Sparrows 30:7-22

Brooks ME, Kristensen K, van Benthem KJ, Magnusson A, Berg CW, Nielsen A, Skaug HJ, Maechler M, Bolker BM (2017) glmmTMB balances speed and flexibility among packages for zero-inflated generalized linear mixed modeling. R J 9:378-400

Chace JF, Walsh JJ (2006) Urban effects on native avifauna: a review. Landsc Urban Plan 74:46-69. https://doi.org/10.1016/j.landurbplan. 2004.08.007

Chamberlain DE, Toms MP, Cleary-McHarg R, Banks AN (2007) House sparrow (Passer domesticus) habitat use in urbanized landscapes. J Ornithol 148:453-462. https://doi.org/10.1007/ s10336-007-0165-x

Charter M, Izhaki I, Ben Mocha Y, Kark S (2016) Nest-site competition between invasive and native cavity nesting birds and its implication for conservation. J Environ Manage 181:129-134. https://doi. org/10.1016/j.jenvman.2016.06.021

De Laet J, Trappeniers B (2019) The realisation of 'green stepping stones' to safe the urban House Sparrow. Intern Stud Sparrows 43:31-32

Eroski Consumer (2008) Contenedores de residuos soterrados (Underground rubbish containers). https://www.consumer.es/medioambiente/contenedores-de-residuos-soterrados.html. Accessed 20 Dec 2019

Francis CD, Barber JR (2013) A framework for understanding noise impacts on wildlife: an urgent conservation priority. Front Ecol Environ 11:305-313. https://doi.org/10.1890/120183

Fox J, Weisberg S (2019) An R companion to applied regression, 3rd edn. Sage, Thousand Oaks, California

García-Hernández M, de la Calle-Vaquero M, Yubero C (2017) Cultural Heritage and Urban Tourism: Historic City Centres under Pressure. Sustainability 9:1346. https://doi.org/10.3390/su9081346

Gaston KJ, Smith R, Thompson K, Warren P (2005) Urban domestic gardens (II): Experimental tests of methods for increasing biodiversity. Biodivers Conserv 14:395-413. https://doi.org/10.1007/ s10531-004-6066-x

Gibbons DW, Gregory RD (2006) Birds. In: Sutherland WJ (ed) Ecological Census Techniques: a handbook, 2nd edn. Cambridge University Press, University of East Anglia, Norwich, pp 324-328

González-Torre PL, Adenso-Díaz B, Ruiz-Torres A (2003) Some comparative factors regarding recycling collection systems in regions of the USA and Europe. J Environ Manage 69:129-138

Haemig PD, de Luna SS, Blank H, Lundqvist H (2015) Ecology and phylogeny of birds foraging at outdoor restaurants in Sweden. Biodivers Data J 3:e6360. https://doi.org/10.3897/BDJ.3.e6360

Herrera-Dueñas A, Pineda J, Antonio MT, Aguirre JI (2015) The relationship between house sparrow and the city: why urban populations are on decline? Talk session presentation at the 10th Conference of the European Ornithologists' Union, Badajoz, Spain, 24-28 August

Herrera-Dueñas A, Pineda-Pampliega J, Antonio-García MT, Aguirre JI (2017) The influence of urban environments on oxidative stress balance: A case study on the House Sparrow in the Iberian Peninsula. Front Ecol Evol 5:1-10. https://doi.org/10.3389/fevo.2017. 00106

Instituto Nacional de Estadística (2019) INE base. Demografía y población. Padrón. Población por municipios (Demography and population. Census. Population by municipalities). https://www. ine.es/dynt3/inebase/index.htm?padre=525. Accessed 14 Dec 2019

Interesting Engineering (2017) UK's Biggest Underground Bin System Eliminates the Need For 9,000 Wheelie Bins. https:// interestingengineering.com/uks-biggest-underground-bin-systemeliminates-the-need-for-9000-wheelie-bins. Accessed 20 Dec 2019

INTHERWASTE (2019) Collection of Good Practices for Waste Management in Urban Heritage Sites. Interreg Europe, Lille. https:// www.interregeurope.eu/fileadmin/user_upload/tx_tevprojects/ library/file_1553777482.pdf. Accessed 12 Jan 2021

Isaksson C (2018) Impact of Urbanization on Birds. In: Tietze DT (ed) Bird Species. How they arise, modify and vanish. Springer Open, Cham, pp 235-257

ISWA (2013) International Solid Waste Association Report 2013 (ISWA Report 2013). ISWA, Rotterdam. https://www.iswa.org/ fileadmin/galleries/Publications/ISWA_Reports/ISWA_Report_ 2013.pdf. Accessed 20 Dec 2019

Legendre P, Legendre L (1998) Numerical Ecology, 2nd edn. Elsevier Science, Amsterdam

López-Pomares A, López-Iborra GM, Martín-Cantarino C (2015) Irrigation canals in a semi-arid agricultural landscape surrounded by wetlands : Their role as a habitat for birds during the breeding season. J Arid Environ 118:28-36. https://doi.org/10.1016/j.jaridenv. 2015.02.021

Lüdecke D (2019) Package "sjstats". https://cran.rproject.org/web/ packages/sjstats/sjstats.pdf. Accessed 14 Dec 2019

Lüdecke D, Makowski D, Waggoner P (2019) Package "performance". https://cran.r-project.org/web/packages/performance/performance. pdf. Accessed 14 Dec 2019

McKinney ML (2002) Urbanization, biodiversity and conservation. Bioscience 52:883-890. https://doi.org/10.1641/0006-3568(2002) 052[0883:UBAC]2.0.CO;2

Moudrá L, Zasadil P, Moudrý V, Šálek M (2018) What makes new housing development unsuitable for house sparrows (Passer domesticus)? Landsc Urban Plan 169:124-130. https://doi.org/ 10.1016/j.landurbplan.2017.08.017

Murgui E (2007) Factors influencing the bird community of urban wooded streets along an annual cycle. Ornis Fenn 84:66-77

Murgui E (2009) Seasonal patterns of habitat selection of the House Sparrow Passer domesticus in the urban landscape of Valencia (Spain). J Ornithol 150:85-94. https://doi.org/10.1007/ s10336-008-0320-z

Murgui E, Hedblom M (2017) Ecology and Conservation of Birds in Urban Environments. Springer International Publishing, Cham

Narango DL, Tallamy DW, Marra PP (2018) Nonnative plants reduce population growth of an insectivorous bird. PNAS 115:1154911554. https://doi.org/10.1073/pnas.1809259115

Nilsson P (2011) Waste Collection: Equipment and Vehicles. In: Christensen TH (ed) Solid Waste Technology \& Management. Wiley, New Jersey, pp 277-295

O'Hara RB (2009) How to make models add up - a primer on GLMMs. Ann Zool Fenn 46:124-137

Pauleit S, Ennos R, Golding Y (2005) Modelling the environmental impacts of urban land use and land cover change a study in Merseyside, UK. Landsc Urban Plan 71:295-310. https://doi.org/10. 1016/j.landurbplan.2004.03.009

Pires A, Martinho G, Rodrigues S, Gomes MA (2019) Sustainable Solid Waste Collection and Management. Springer Nature Switzerland AG, Cham, Switzerland. 
R Core Team (2020) R: A language and environment for statistical computing. R Foundation for Statistical Computing, Vienna, Austria. https://www.r-project.org/. Accessed 29 Dec 2020

Reynolds SJ, Galbraith JA, Smith JA, Jones DN (2017) Garden bird feeding: insights and prospects from a north-south comparison of this global urban phenomenon. Front Ecol Evol 5:24. https://doi. org/10.3389/fevo.2017.00024

Sætre G-P, Riyahi S, Aliabadian M, Hermansen JS, Hogner S, Olsson U, Gonzalez MF, Sæther SA, Trier CN, Elgvin TO (2012) Single origin of human commensalism in the house sparrow. J Evol Biol 25:788-796. https://doi.org/10.1111/j.1420-9101.2012.02470.x

Schroeder J, Nakagawa S, Cleasby IR, Burke T (2012) Passerine birds breeding under chronic noise experience reduced fitness. PLoS ONE 7:e39200. https://doi.org/10.1371/journal.pone.0039200

Shaw LM, Chamberlain D, Evans M (2008) The House Sparrow Passer domesticus in urban areas: Reviewing a possible link between post-decline distribution and human socioeconomic status. J Ornithol 149:293-299. https://doi.org/10.1007/s10336-008-0285-y

Shaw LM, Chamberlain D, Conway G, Toms M (2011) Spatial distribution and habitat preferences of the House Sparrow, Passer domesticus, in urbanised landscapes, BTO Research Report 599. British Trust for Ornithology, Thetford.

Shochat E, Lerman SB, Anderies JM, Warren PS, Faeth SH, Nilon CH (2010) Invasion, Competition, and Biodiversity Loss in Urban Ecosystems. Bioscience 60:199-208. https://doi.org/10.1525/bio. 2010.60.3.6

SIGPAC (2019) Visor SIGPAC. Versión 3.5. Ministerio de Agricultura, Alimentación y Medio Ambiente. Gobierno de España, Madrid. (SIGPAC Viewer. Version 3.5. Ministry of Agriculture, Food and Environment. Spanish Government, Madrid). http://sigpac.mapa. es/fega/visor/\#. Accessed 15 Dec 2019

Spelt A, Soutar O, Williamson C, Memmott J, Shamoun-Baranes J, Rock P, Windsor S (2021) Urban gulls adapt foraging schedule to human-activity patterns. Ibis 163:274-282. https://doi.org/10. 1111/ibi.12892

Summers-Smith JD (2003) The decline of the House Sparrow: A review. Br Birds 96:439-446
Summers-Smith JD (2005) Changes in the house sparrow population in Britain. Intern Stud Sparrows 30:23-37

The Hague (2017) From kerbside collection to underground containers. The Hague Municipality, The Hague. https://www.denhaag.nl/en/ waste-and-recycling/household-rubbish/from-kerbside-collectionto-underground-containers.htm. Accessed 20 Dec 2019

Thomas RL, Fellowes MDE, Baker PJ (2012) Spatio-Temporal Variation in Predation by Urban Domestic Cats (Felis catus) and the Acceptability of Possible Management Actions in the UK. PLoS ONE 7:e49369. https://doi.org/10.1371/journal.pone.0049369

Tortosa FS, Caballero JM, Reyes-López J (2006) Effect of Rubbish Dumps on Breeding Success in the White Stork in Southern Spain. Waterbirds 25:39-43. https://doi.org/10.1675/1524-4695(2002) 025[0039:EORDOB] 2.0.CO;2

United Nations (2018) The World's Cities in 2018-Data booklet (ST/ ESA/ SER.A/417). United Nations, Department of Economic and Social Affairs, Population Division. New York, EEUU

Vangestel C, Braeckman BP, Matheve H, Lens L (2010) Constraints on home range behaviour affect nutritional condition in urban house sparrows (Passer domesticus). Biol J Linnean Soc 101:41-50. https://doi.org/10.1111/j.1095-8312.2010.01493.x

Verbeeck K, Orshoven J, Hermy M (2011) Measuring extent, location and change of imperviousness in urban domestic gardens in collective housing projects. Landsc Urban Plan 100:57-66. https:// doi.org/10.1016/j.landurbplan.2010.09.007

Vincent K (2005) Investigating the causes of the decline of the urban house sparrow Passer domesticus in Britain. PhD Thesis, De Montfort University, Leicester

Whelan CJ, Brown JS, Hank AE (2015) Diet preference in the House Sparrow Passer domesticus: hooked on millet ? Bird Study 62:569-573. https://doi.org/10.1080/00063657.2015.1089838

Zuur AF, Ieno EN, Elphick CS (2010) A protocol for data exploration to avoid common statistical problems. Methods Ecol Evol 1:3-14. https://doi.org/10.1111/j.2041-210X.2009.00001.x 